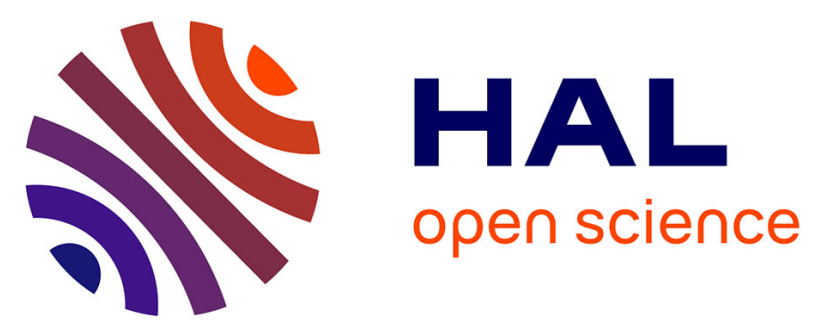

\title{
Combining X-ray microtomography with the finite elements method to study damage and cracking in structural materials
}

Henry Proudhon, Jia Li, Yoann Guilhem, Lucien Laiarinandrasana, Thilo F. Morgeneyer, Wolfgang Ludwig, A. Roos, Samuel Forest

\section{To cite this version:}

Henry Proudhon, Jia Li, Yoann Guilhem, Lucien Laiarinandrasana, Thilo F. Morgeneyer, et al.. Combining X-ray microtomography with the finite elements method to study damage and cracking in structural materials. TMS 2013 - 142nd annual meeting \& exhibition, Mar 2013, San Antonio, Texas, United States. pp.1165-1173, 10.1002/9781118663547.ch142 . hal-00874745

\section{HAL Id: hal-00874745}

https://hal-mines-paristech.archives-ouvertes.fr/hal-00874745

Submitted on 9 Nov 2018

HAL is a multi-disciplinary open access archive for the deposit and dissemination of scientific research documents, whether they are published or not. The documents may come from teaching and research institutions in France or abroad, or from public or private research centers.
L'archive ouverte pluridisciplinaire HAL, est destinée au dépôt et à la diffusion de documents scientifiques de niveau recherche, publiés ou non, émanant des établissements d'enseignement et de recherche français ou étrangers, des laboratoires publics ou privés. 


\title{
Combining X-Ray Microtomography with the Finite Elements Method to Study Damage and Cracking in Stuctural Materials
}

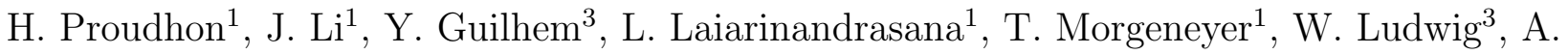 \\ Roos $^{2}$, S. Forest ${ }^{1}$ \\ ${ }^{1}$ MINES ParisTech, Centre des Materiaux, UMR 7633 CNRS, BP 87, F-91003 Evry Cedex, \\ France \\ ${ }^{2}$ ONERA, 29 avenue de la Division Leclerc, Chatillon FR-92322, France \\ ${ }^{3}$ Universite de Lyon, INSA-Lyon, MATEIS, UMR 5510 CNRS, 25 avenue Jean Capelle, \\ F-69621 Villeurbanne Cedex, France
}

Keywords: X-ray Microtomography, Finite Element, Cracking Damage, Structural Materials

\begin{abstract}
The increasing popularity and capability of X-ray tomography to image cracks and damage in three dimensions in a non destructive fashion brings forward a new way to validate large scale material failure simulations. A wide range of crack propagation case studies will be presented, ranging from cracks in notched polymer specimens and structural aluminum alloys to short crack propagation in a titanium alloy polycrystal. The incredibly rich knowledge brought at the micron scale by in situ imaging using either absorption, phase or diffraction contrasts, while the crack progresses, can often serve as direct input for full field simulations. Cracking mechanisms, direction and growth rate can therefore be tested and modeled at the appropriate scale (crazing in polymer materials, crystal plasticity in individual grains or linear elastic fracture mechanics for larger cracks). Meshing strategies and high performance computing will also be discussed.
\end{abstract}

\section{D damage distribution and orientation in deformed semi-crystalline polymers}

Studying the micro-structural and damage evolutions under straining is a key to asses the mechanical and failure properties of polymer materials. To improve engineering material models, these evolutions have to be linked to the stress/strain fields applied to the sample. Here, high resolution X-ray tomography has been used to reveal damage in three dimensions in semi-crystalline PolyAmide 6 (PA6) notched specimens issued from interrupted tensile tests. These latter were used instead of classical uniaxial tensile specimens in order to set a controlled multiaxial stress state within the necked region. Recorded tomographic images are processed using image analysis to retreive the void volume fraction as well as the spatial distribution and orientation of voids, as a function of the position within the sample with respect to the notch root. Experimental results are compared to finite element calculations using damage based constitutive relationships.

\section{Materials and methods}

The PA6 under study was selected due to the quality of the images obtained by Synchrotron Radiation Tomography (SRT) carried out at the European Synchrotron Radiation Facilities (ESRF). The physico-chemical properties, as well as the description of the tomography 
technique were published in [1]. Here, a series of interrupted tests were carried on circumferentially notched specimens with two values of initial notch root radius $R=4 \mathrm{~mm}$ and $R=0.45 \mathrm{~mm}$. The net section radius, in both cases was $a=2 \mathrm{~mm}$. These specimens are called "notched tensile R" (NT4 and NT0.45) according to the initial notch root radius $R$ value. A tension machine with a load cell and the crosshead displacement measurements was used to deform the samples well after the peak stress, at the end of the stress softening. After unloading and specimen removal, deformed samples were, first photographed in order to determine the characteristic length of the volume of interest, then, scanned at ESRF in Grenoble (France). SRT was carried out using the ID19 tomograph. A local tomographic setup was used to avoid a cutting of the sample and the sample was moved within the field of view between each scan to image different zones of the deformed regions (see inset on figure 1). A tomographic scan corresponds to 1500 radiographs recorded over a $180^{\circ}$ rotation of the sample. The distance between the specimen and the camera was set to $25 \mathrm{~mm}$ which lead to a reasonable amount of phase contrast helping to highlight voids present inside the sample. A restricted region of $1024 \times 512$ pixels from the CCD camera was used to form the radiograph, resulting in 3 minutes scan duration with an isotropic reconstructed pixel size of $0.7 \mu \mathrm{m}$. Hence, in the following tomographic images, the width corresponding to the diameter of the maximum reconstructed 3D volume was of $716 \mu \mathrm{m}$ whereas the height was of $358 \mu \mathrm{m}$ (see figure 1). Image analysis inhouse automated routines were used as a post processing to quantify the void characteristics such as the void volume fraction $(f)$ and the orientation of void columns.

Experimental results

Figure 1 illustrates the main results on a reconstructed volume located near the notch root of the NT4 specimen. On both views (figure 1a-b), voids are in black and the main features observed are as follows:

- voids appear elongated in the tensile direction; voids arrange in columns separated by thin walls of material;

- the maximum void volume fraction is located in the centre of the specimen;

- a gradual change of orientation of the void columns is observed when approaching the notch surface (figure 1b).

Unlike NT4, the radial distribution of void volume fraction for NT0.45 specimen present a maximum located somewhere in between the centre and the notch root radius. Radial distributions of the void volume fraction $(f)$ and the void columns orientation $(\theta)$ are depicted in figure 2. The radius is normalized by the deformed maximum radius measured before the scan $\left(r_{s}\right)$ whereas $f$ is normalized by the maximum value reached for each specimen. Full symbols are related with experiments while open symbols depict simulation results (see next section). In figure $2 \mathrm{a}$, it can be observed that the location of the maximum void volume fraction $\left(f / f_{\max }=1\right)$ depends on the initial notch root radius: in the centre for NT4 and near the notch root surface for NT0.45. Figure $2 \mathrm{~b}$ plots the radial distribution of the angle measured between the tensile direction and the void columns axis.

\section{Modeling}

Modeling of notched specimens can be achieved either by using formulae (analytical) or with the help of finite element (FE) analysis [2]. Analytical modeling is available under isochoric 
a)

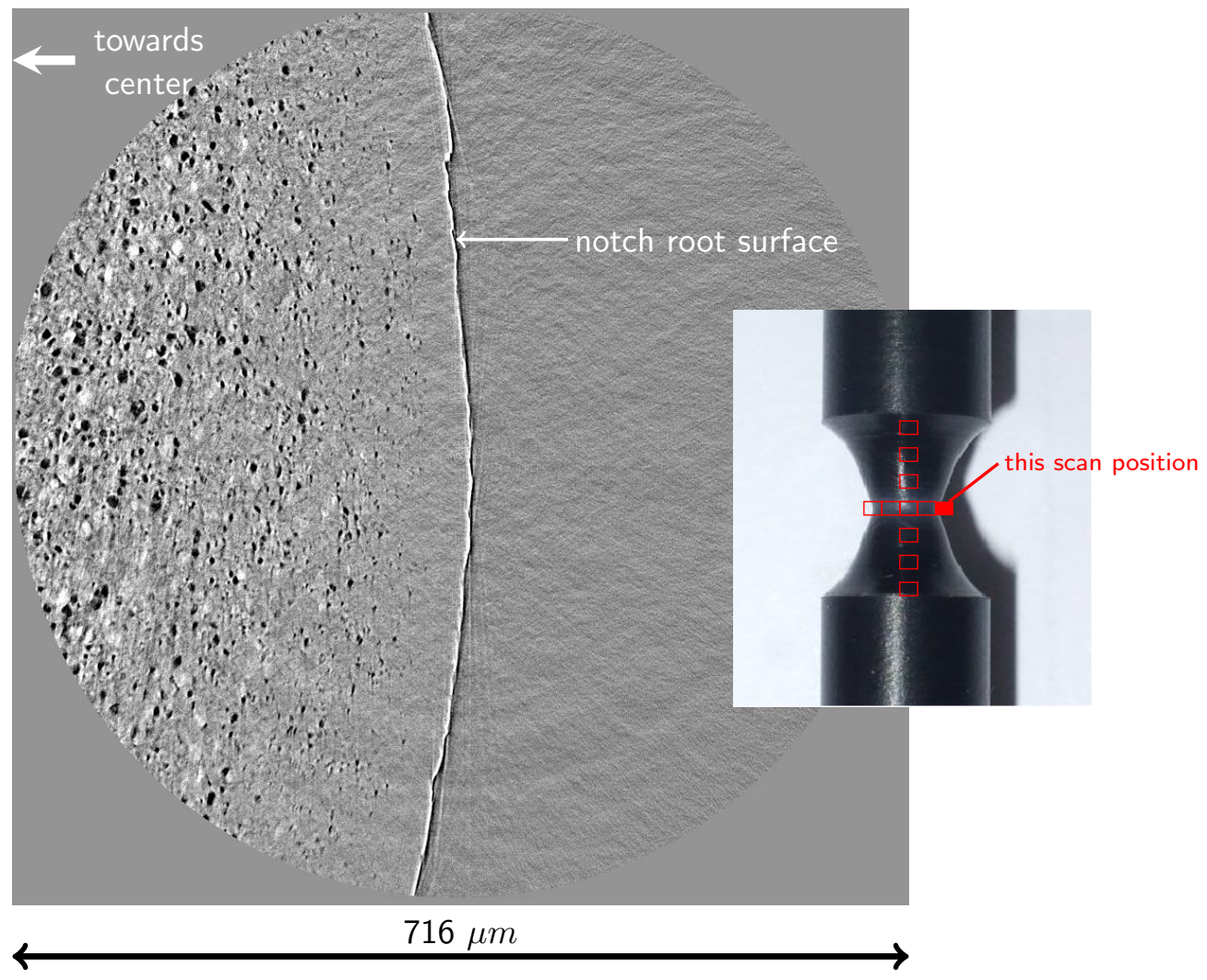

b)

b)

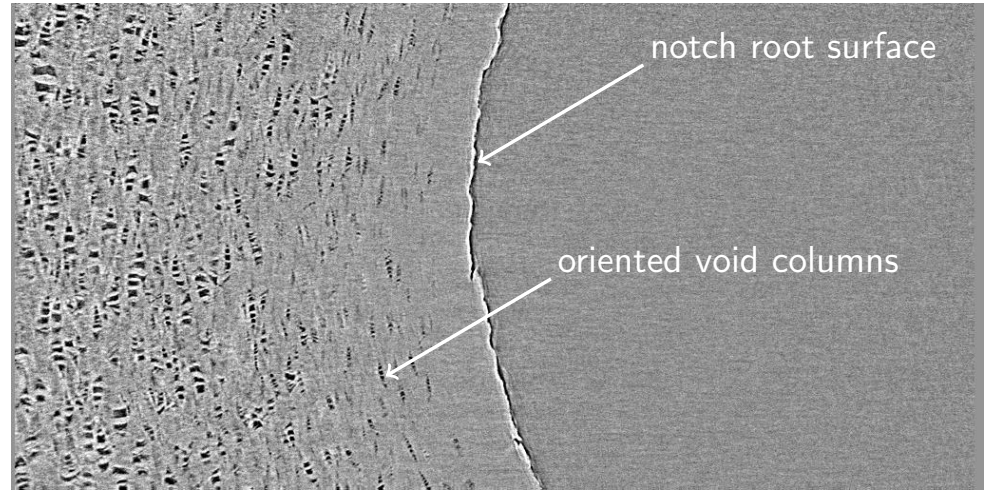

Figure 1: Examples of reconstructed tomographic slices in the NT4 specimen (a) radial view (perpendicular to the loading direction) (b) longitudinal view; the inset shows the position of the various scans carried out in the deformed samples.
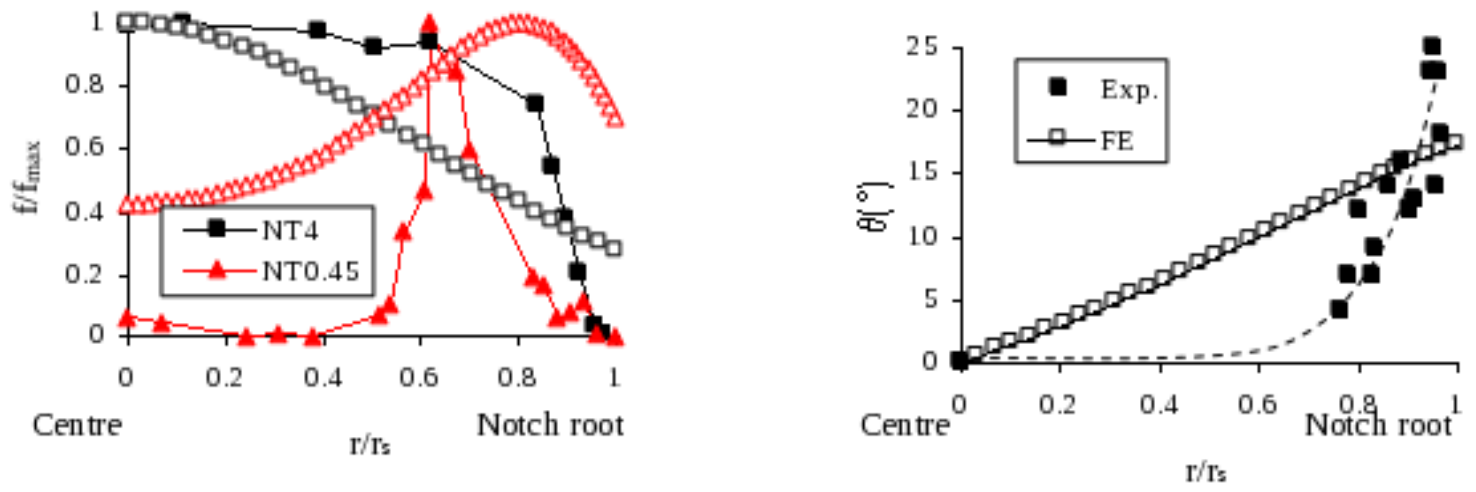

Figure 2: Radial distributions of (left) void volume fraction for NT4 and NT0.45; (right) void columns orientation for NT4 (FE results are presented with open symbols). 


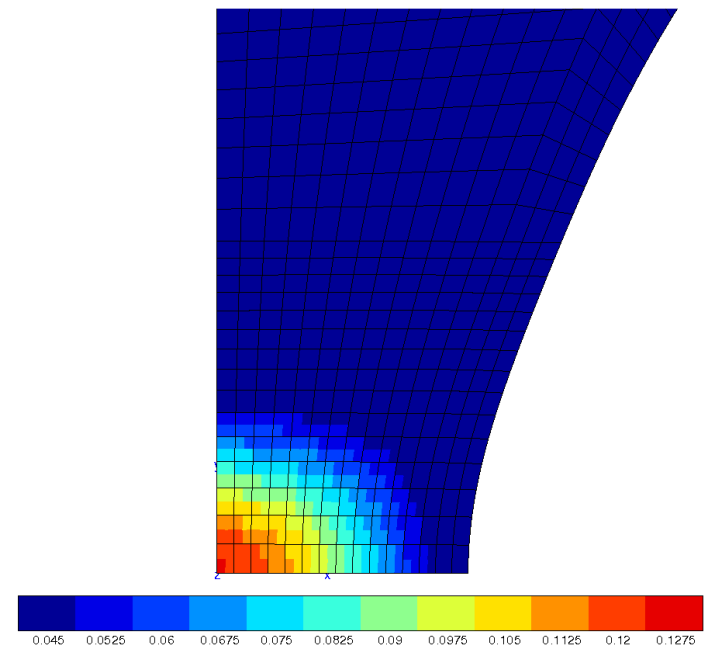

(a) NT4

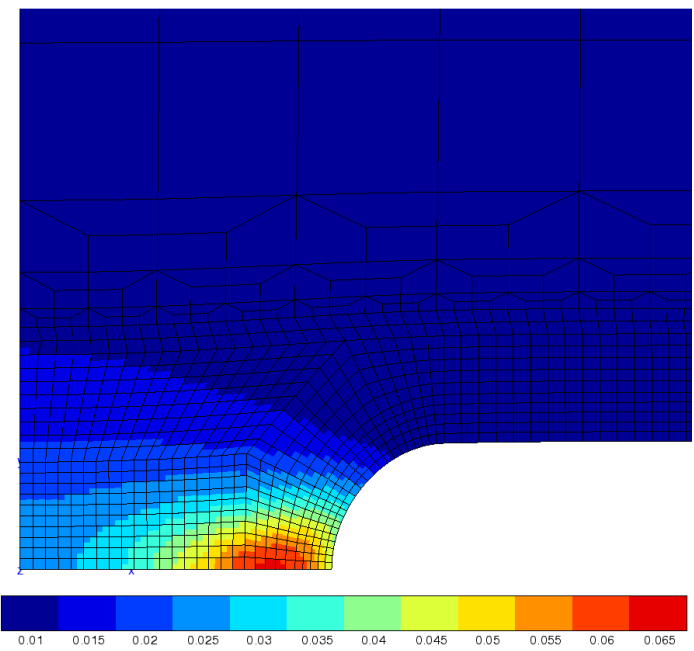

(b) NT045

Figure 3: Illustration of the change in the location of maximum damage by using the contour maps of the void volume fraction $f$.

and small strain hypotheses [2]. In this work, FE modeling was used to overcome these limitations. To this end, constitutive equations involving damage modeling (by handling $f$ as internal variable) were implemented in the z-set software suite code [3].

Material parameters have been tuned to reproduce the macroscopic behaviour (load vs. crosshead displacement) as well as the distribution of the porosity. Results can be observed in figure 3 where contour maps of the porosity $f$ are displayed. Figure 3 gives also an overview of the radial distributions of damage for which experimental profiles were already shown in figure 2a. Although the numerical slopes are generally smoother than that of experimental data, figure $2 \mathrm{a}$ shows that the FE model is able to predict the change in the location of the maximum damage, regarding the initial notch radius.

The next step consists of checking which mechanical parameter is consistent with void column orientation (figure 2b). Previous study [2] showed that the radial distribution of voids for NT4 specimen follows the shape of the largest principal stress plot, whereas the largest principal strain distribution is rather "flat" (homogeneous strain in the net section). An attempt was then made here to plot the angle corresponding to the eigenvector of the largest principal stress and superimpose it to the orientation of void columns (figure $2 \mathrm{~b}$ ).

Although the numerical results seem to show quasi-linear evolution, the same trend is observed and the numerical values of orientation angle in the vicinity of the notch root are within the scatter band of the experimental measures. It can be concluded that both damage radial distribution and damage orientation coincide with the field of largest principal stress. Therefore, the damage observed here can be considered as stress markers.

\section{Outlook}

The micro-structural evolutions of PA6 during monotonic tensile tests were analyzed using high resolution tomography $\mathrm{X}$. Images in 3D allowed to specify the morphology, the distribution and the orientation of voids column. Void volume fraction and void column orientation were plotted against the radial direction within the net section. FE results, with a dedicated damage based model, were in good agreement with the experimental data at both macroscopic and microscopic scales. The damage distribution and orientation coincide with the 
largest principal stress field, given by the FE analysis.

\section{Microstructurally short crack propagation in a $\beta$-titanium alloy}

Microstructure in polycrystalline materials, such as grain size, grain shape and crystallographic texture strongly influences the mechanical behaviours of materials and the path of short cracks propagation. For instance, it is more and more admited that high twist misorientation angles correspond to stronger barrier to fatigue crack propagation $[4,5]$. Moreover, numerous experiments demonstrated that the well-established theory based on linear elastic fracture mechanics (LEFM) valid for long cracks and confined plasticity, cannot predict the fatigue behaviour of small cracks. In-situ X-ray tomography experiments were carried out to characterize the three dimensional grain shape, their orientation and visualise the 3D shape of short fatigue cracks. The aim of this part is to show the progress of small fatigue crack growth simulations using a 3D microstructural mesh and crystal plasticity modeling.

\section{Materials}

The material selected in this work is a near beta titanium alloy Ti55531 which has an appropriate density required by the tomographic acquisition. The sample used in this work was forged, annealed at $843^{\circ} \mathrm{C}$ for 2 hours under vacuum and then air cooled. As a result, a fully static recrystallization of the $\beta$ phase was obtained with a mean grain diameter of $65 \mu \mathrm{m}$ that is suitable to form diffraction spots that appear clear and undistorted during diffraction contrast tomography acquisition [6]. The crystal structure of Ti55531 is BCC in which slip may occur on 48 slip systems: 12 systems in the $\langle 111\rangle\{110\}$ family, 12 systems in the $\langle 111\rangle\{112\}$ family and 24 systems in the $\langle 111\rangle\{123\}$ family.

\section{Experimental results}

The in-situ experiments were performed at the ESRF in Grenoble (France) on the ID19 beam line. Two types of tomography were used in this work: Phase Contrast Tomography (PCT) and Diffraction Contrast Tomography (DCT). The X-ray DCT experiment allows to characterise the microstructure of a polycrystalline sample before any fatigue damage. This technique provides the information about 3D grain shapes and crystallographic orientations that will be used in the FE model. A $25 \times 140 \mu \mathrm{m}$ rectangular notch has been machined by Focused-Ion Beam Machining at the middle of the sample in order to localise stress, and crack initiation and subsequent propagation during the in-situ experiment. The PCT experiment with interrupted in-situ fatigue tests enables then to detect cracks in regions where the crack opening is below micrometer range [7] at each stage.

The energy of synchrotron radiation in the DCT experiment was $35 \mathrm{keV}$. During a rotation of the sample of $360^{\circ}$ around the vertical axis, 7200 images were acquired from which the grains were reconstructed, see figure 4a. The height of the illumination field was about $540 \mu \mathrm{m}$. The volume contains approximately 400 grains and the pixel size is about $1.4 \mu \mathrm{m}$. For the PCT experiment, the energy was $50 \mathrm{keV}$. The initiation of a crack was observed after $28 \mathrm{k}$ cycles. However, the propagation stages will not be simulated in this work.

\section{Meshing procedure}

The three dimensional mesh is constructed from the tomographic images using a multimaterial marching cube algorithm. The crack surface (the thickness of the notch is assumed 
to be negligible), whose dimensions were determined from absorption images of the DCT experiment was meshed independently. This meshed surface was then used for cutting the initial mesh of the polycrystal using boolean operations, see figure 4a. The cracked aggregate was remeshed several times using a combination of YAMS ${ }^{\mathrm{TM}}$, Meshadapt ${ }^{\mathrm{TM}}$ and GHS3D $^{\mathrm{TM}}$ to achieve the desired mesh refinement around the crack tip while preserving the mesh description of the microstructure.

An example of the final mesh obtained for the titanium sample is illustrated in figure $4 \mathrm{~b}$. It contains about 5 million elements with a minimum element size at the crack tip of $1 \mu \mathrm{m}$, while the average element size within the grains is $4 \mu \mathrm{m}$.

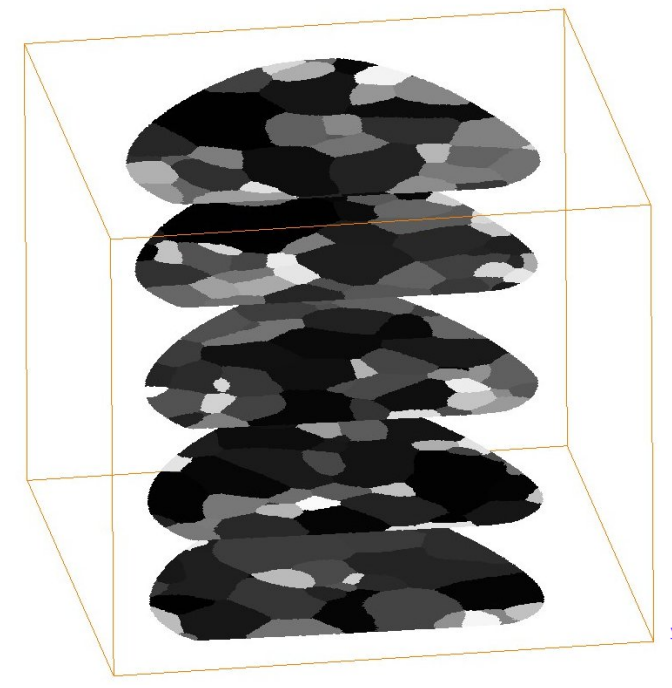

(a)

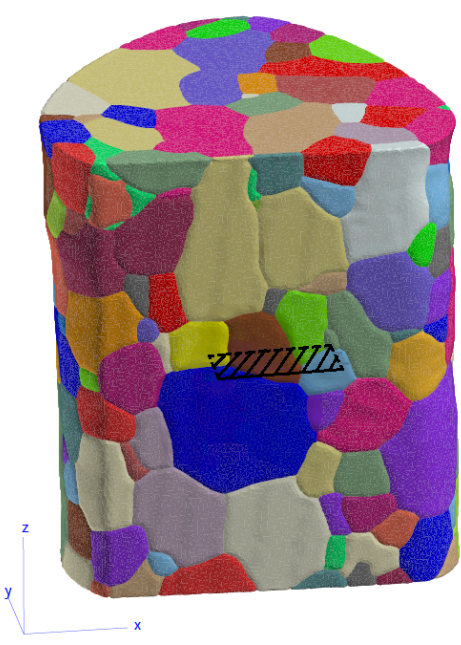

(b)

Figure 4: (a) Example of images of a titanium specimen reconstructed from X-ray diffraction contrast tomography (b) Finite element mesh obtained from the digital image after instertion of the crack.

\section{Modeling}

In order to analyse the activation of slip systems and plastic strain concentrations at the crack tip, a phenomenological crystal plasticity model was selected [8]. Using this type of model in single crystal materials, [9] has investigated the strain localisation at the crack tip under cyclic loading in two and three dimensions in monocrystals. The current study focuses on the applications in polycrystalline materials. A perfectly plastic model behaviour is used to simulate the VST55531 material, constitutive equations are described in this section. In addition, all the calculations were conducted in the small strain framework using the Z-set software suite [10].

The strain tensor $\underset{\sim}{\varepsilon}$ is partitioned into an elastic part $\underset{\sim}{\varepsilon^{e}}$ and a plastic part ${\underset{\sim}{q}}^{p}$ according to:

$$
\underset{\sim}{\varepsilon}={\underset{\sim}{\varepsilon}}^{e}+{\underset{\sim}{\varepsilon}}^{p}
$$

The linear elasticity is described by Hooke's law, with $\underset{\sim}{\mathbf{C}}$ a four-order tensor and $\underset{\sim}{\sigma}$ the Cauchy stress:

$$
\underset{\sim}{\sigma}=\underset{\sim}{\mathbf{C}}:{\underset{\sim}{\varepsilon}}^{e}
$$


The plastic strain is the result of the possible activation of $12\langle 111\rangle\{110\}$ slip systems. In this study, the $\langle 111\rangle\{112\}$ and $\langle 111\rangle\{123\}$ slip systems are not considered.

$$
\stackrel{\dot{\varepsilon}}{p}^{p}=\sum_{s=1}^{12} \dot{\gamma}^{s} \underline{\sim}^{s} \quad \text { with } \quad{\underset{\sim}{\mathbf{m}}}^{s}=\frac{1}{2}\left(\underline{n}^{s} \otimes \underline{l}^{s}+\underline{l}^{s} \otimes \underline{n}^{s}\right)
$$

where $\mathbf{m}^{s}$ is the orientation tensor defined by the slip plane $\underline{n}^{s}$ and the slip direction $\underline{l}^{s}$ in each system $s$, and $\dot{\gamma}^{s}$ is the slip rate defined by a power law:

$$
\dot{\gamma}^{s}=\operatorname{sign}\left(\tau^{s}\right)\left\langle\frac{\left|\tau^{s}\right|-\tau_{0}}{K}\right\rangle^{n}
$$

where $\mathrm{K}$ and $\mathrm{n}$ are Norton's parameters. $\tau_{0}$ is the critical resolved shear stress and $\tau^{s}$ is the resolved shear stress in the form of: $\tau^{s}=\underset{\sim}{\sigma}: \mathbf{m}^{s}$

\section{$\underline{\text { Results and outlook }}$}

The F.E. calculation features 2648745 degrees of freedom for linear elements and 4978356 degrees of freedom for quadratic elements around the crack. These calculations were carried out using multithreading over $8 \mathrm{CPU}$ and a total of $256 \mathrm{~Gb}$ of memory. After imposing a displacement of $5 \mu \mathrm{m}$ at the top of the sample in the tensile direction and blocking vertical movement at the bottom, a first result of cumulative plastic slip in the vicinity of crack front inside the volume and the slip system activities have been analysed. It can be observed that the plastic slip accumulates more significantly in the grain on the left hand side of the crack than the one on the right side. This grain, in which the crack would probably propagate will be analysed in detail in this part.

To analyze the effect of the free surface in the calculation, two vertical slices were made at different depths of volume. The accumulated plastic strain on the surface using linear elements is plotted on figures $5 \mathrm{a}$ and $5 \mathrm{~b}$ represents the plastic slip state on a slice at $20 \mu \mathrm{m}$ below the sample surface. Comparing the two maps on figure 5, one may notice that the direction of slip localisation lines has changed between the surface and inside the sample. This change of direction can be observed clearly by the analysis of the more precise quadratic element calculation with the same boundary conditions, see figure 6 .

For future work, in order to simulate the complex behaviour of short fatigue crack propagation and bifurcation, a continuous damage model based on the resolved shear stress and the plastic slip in each systems will be applied in the analysis of FE simulations, and validated by comparing the fracture surface orientations and growth rates during in-situ fatigue experiments. The influence of boundary conditions on the details of plastic slip accumulation at the cracktip will be determined quantitatively, and detailed parameters for the crystal plasticity model will be identified from a series of tension-compression tests on macroscopic VST55531 samples.

\section{References}

[1] L. Laiarinandrasana, T. F. Morgeneyer, H. Proudhon, and C. Regrain. Damage of semicrystalline polyamide 6 assessed by 3D X-ray tomography: From microstructural evolution to constitutive modeling. Journal of Polymer Science Part B: Polymer Physics, 48(13):1516-1525, 2010. 


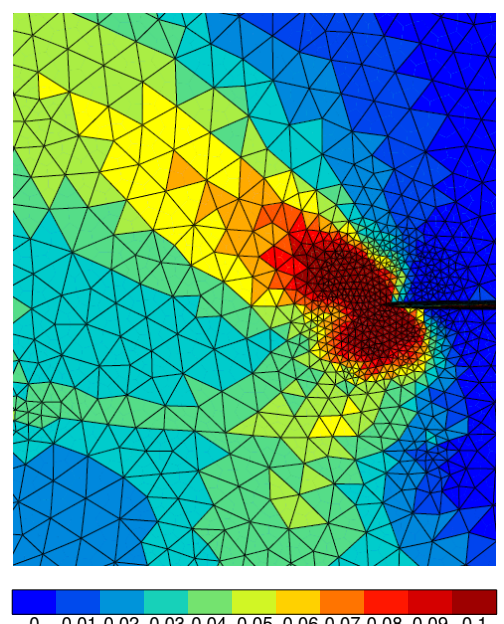

(a)

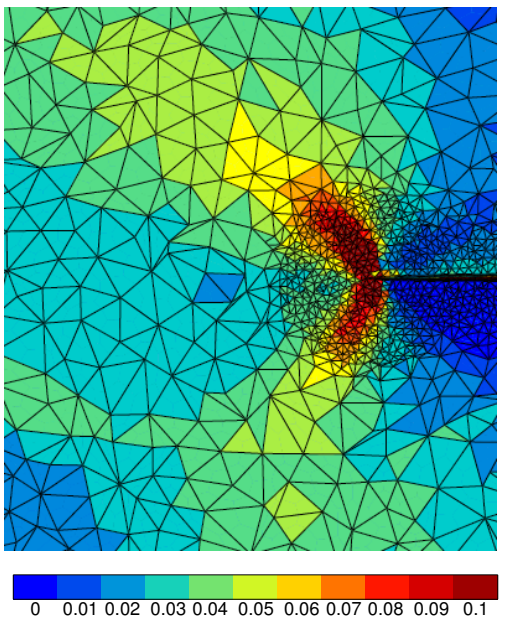

(b)

Figure 5: Example of vertical slices of the sample with linear elements mapped by accumulated plastic strain. a) Accumulated plastic strain on the surface of the sample. b) Accumulated plastic strain inside the sample at $20 \mu \mathrm{m}$ below the sample surface.

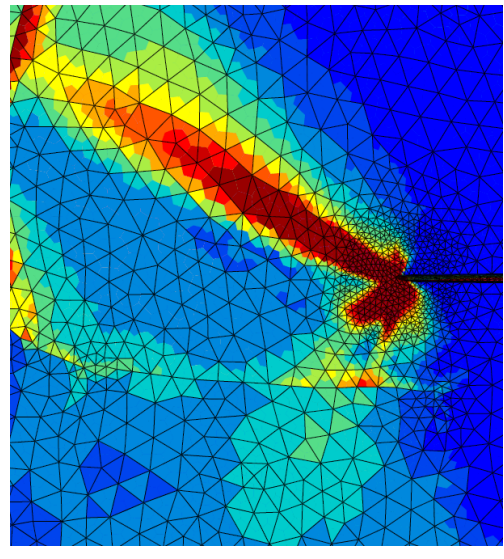

$0.010 .020 .030 .04 \quad 0.050 .060 .070 .08 \quad 0.09 \quad 0.1$

(a)

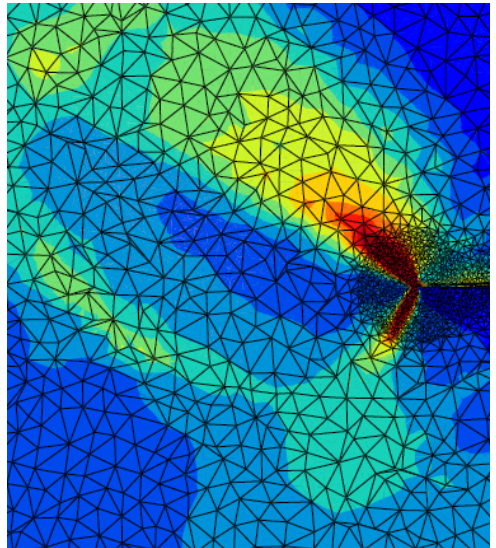

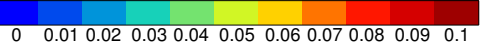

(b)

Figure 6: Example of vertical slices of the sample with quadratic elements mapped by accumulated plastic strain. a) Accumulated plastic strain on the surface of the sample. b) Accumulated plastic strain inside the sample at $20 \mu \mathrm{m}$ below the sample surface.

[2] G. Boisot, L. Laiarinandrasana, J. Besson, C. Fond, and G. Hochstetter. Experimental investigations and modeling of volume change induced by void growth in polyamide 11. International Journal of Solids and Structures, 48(19):2642-2654, 2011.

[3] J. Besson and R. Foerch. Large scale object-oriented finite element code design. Computer Methods in Applied Mechanics and Engineering, 142(1-2):165-187, 1997.

[4] T. Zhai, A. J. Wilkinson, and J. W. Martin. A crystallographic mechanism for fatigue crack propagation through grain boundaries. Acta Materialia, 48(20):4917-27, dec 2000. 
[5] E. Ferrié, J.-Y. Buffière, W. Ludwig, A. Gravouil, and L. Edwards. Fatigue crack propagation: In situ visualization using X-ray microtomography and 3D simulation using the extended finite element method. Acta Materialia, 54(4):1111-1122, 2006.

[6] W. Ludwig, A. King, M. Herbig, P. Reischig, J. Marrow, L. Babout, E. M. Lauridsen, H. Proudhon, and J. Y. Buffière. Characterization of polycrystalline materials using synchrotron X-ray imaging and diffraction techniques. JOM, 62(12):22-28, December 2010.

[7] P. Cloetens, M. Pateyron-Salomé, J.-Y. Buffière, G. Peix, J. Baruchel, F. Peyrin, and M. Schlenker. Observation of microstructure and damage in materials by phase sensitive radiography and tomography. Journal of Applied Physics, 81(9):5878-5886, May 1997.

[8] L. Meric and G. Cailletaud. Single crystal modeling for structural calculations: Part 2 -finite element implementation. Journal of Engineering Materials and Technology, 113(1):171-182, 1991.

[9] S. Flouriot, S. Forest, and L. Remy. Strain localization phenomena under cyclic loading: Application to fatigue of single crystals. Computational Materials Science, 26:61-70, 2003. 11th International Workshop on Computational Mechanics of Materials.

[10] Mines ParisTech, ONERA, and NorthWest Numerics: Z-SeT/ZeBuLoN finite element code. 